\title{
Geographical indications: A first assessment of the impact on rural development in Italian NUTS3 regions
}

\author{
Leonardo Cei $^{\mathrm{b}, *}$, Gianluca Stefani ${ }^{\mathrm{a}}$, Edi Defrancesco ${ }^{\mathrm{b}}$, Ginevra Virginia Lombardi ${ }^{\mathrm{a}}$ \\ ${ }^{\text {a }}$ Department DISEI, University of Firenze, 50127, Italy \\ ${ }^{\mathrm{b}}$ Department TESAF, University of Padova, 35020, Italy
}

\section{A R T I C L E I N F O}

\section{Keywords:}

Geographical indications

Impact evaluation

Rural development

Differences in differences

\begin{abstract}
A B S T R A C T
Geographical indications (GIs) are a 25 years old European policy instrument and one objective of GIs is to foster rural development. In this respect, very few studies have quantitatively investigated to what extent this policy is effective. In fact, the literature is mainly focused on specific GIs, examined through case studies, in an attempt to identify which factors are responsible for the success or failure of specific initiatives. By contrast, the aim of the present study is to quantify the impact of such policy instrument on a single indicator of rural development: the agricultural value added. To assess the impact we firstly built an index measuring the number of GI schemes implemented at the NUTS3 level in the Italian regions. Then, following a difference-in-difference evaluation strategy and relying on an explicit theoretical model, a fixed effect estimator was implemented. The choice of the model, as well as the variables considered, was specified using a directed acyclic graph. The results show that an overall positive effect of GI protection on agricultural value added was identified in Italy, thus providing evidence of a positive impact of the European policy on rural development.
\end{abstract}

\section{Introduction}

Geographical indications (GIs) are a legislative instrument created by the European Union under Regulation(EEC) 2081/92. ${ }^{1}$ Technically a labelling regulation, it is a tool for solving the asymmetric information problem between consumers and producers (OECD, 2000; Bramley, 2011; Giovannacci et al., 2009) and for preventing unfair imitation and misuses of names. On the producer side, GIs are a method to link the product to the images of the production area (environment, culture, landscape), thus exploiting consumer willingness to pay for the latter (Van Ittersum et al., 2003).

Since their introduction, GIs have spread throughout Europe, although at different paces. There is indeed a clear differentiation between the Mediterranean area, which, with its first five producer countries (Italy, France, Spain, Portugal and Greece), accounts for nearly $70 \%$ of all the European registered GI products, and the rest of Europe. The literature provides two main explanations for such a geographic pattern. Lee and Rund (2003) attribute the difference in GI use to climatic factors, which could probably explain even the far longer and well-rooted tradition of Mediterranean countries in using origin designations. Conversely, Parrot et al. (2002) argue that the primary cause should be found in the socio-economic differences between the two areas, i.e., Northern Europe, which is more focused on agricultural productivity and economic efficiency, and Southern Europe, which remains anchored to a tradition where local embeddedness and trust are still important.

The different use of GIs across EU members is linked to different consumer awareness of GIs. As Velčovská and Sadílek (2014) observed, despite no causal relationship being highlighted, the more a country uses PDO (protected designation of origin) and PGI (protected geographical indication) labels, the more its citizens are aware about the significance of these market tools.

The divide is also confirmed in terms of economic importance. In fact, as stated in a 2012 European Commission report (Chever et al., 2012), the two major users of this instrument, namely Italy and France, are those that receive the largest economic share with 6 and 3 billion euros of sales value (wines excluded), respectively.

Despite the North-South divide, the GI sector seems to exhibit a common positive trend, in terms of both quantities produced and revenue (Folkeson, 2005). The above mentioned Commission report states that in 2010 the 1300 European PDO and PGI products accounted for a sales value of approximately 15,790 billion euros, representing $5.7 \%$ of the overall European food and drink sector revenue (Chever et al., 2012). This was accompanied by an increase in consumer awareness of

\footnotetext{
* Corresponding author.

E-mail addresses: leonardo.cei@phd.unipd.it (L. Cei), gianluca.stefani@unifi.it (G. Stefani), edi.defrancesco@unipd.it (E. Defrancesco), gvlombardi@unifi.it (G.V. Lombardi).

${ }^{1}$ Subsequently modified by Regulation (EU) No 510/2006 and the framework Regulation (EU) on quality schemes No $1151 / 2012$.
} 
GI products, which was also documented by the Special Eurobarometer 389 (European Commission, 2012) and with an ever increasing number of applications for new product registration, highlighting the relevance that this instrument has earned in the 25 years of its life.

GIs are supposed to play a significant role in fostering rural local development. This objective is expressly stated in the "whereas" of the original Regulation(EEC) 2081/92, indicating that such certification can benefit production areas in terms of increasing farmers' incomes and counteracting rural exodus. From the perspective of endogenous development, these types of products, especially PDO products, incorporate local resource specificities, both material and immaterial, which are capable of strongly differentiating and characterizing local foods in the market. This process promotes the creation of niche markets where rural areas may be rewarded for their imagery, authenticity or traditionality (Jenkins and Parrott, 1999). In addition, delimitation of the production area allows appropriation of rent by farmers and landowners in the area (Landi and Stefani, 2015).

The aim of this paper is to provide a first quantitative assessment of the economic impact of the EU GI policy on rural development at the country level. Although quantitative assessments of single PDOs can be found in the literature, they focus on specific case studies and provide results that cannot easily be extended to other contexts. Building on the policy impact assessment approach (Shahidur et al., 2010), and guided by a theoretical model, we aim to exploit available statistical data to analyse the overall impact of the GI policy at Italian level using the agricultural value added at the $\mathrm{NUTS}^{2}$ area scale.

The paper is organized as follows: in the next section, we address the topic of the evaluation of GIs as a policy instrument, providing a first assessment of the current state of the art and stating the objectives of our work. The results of the analysis are presented in the third section. Finally, some considerations regarding the implications of our work and recommendations for further research are presented in the last section.

\section{Economic impact of GIs}

As stated by Gertler et al. (2011) "Development programs and policies are typically designed to change outcomes, for example to raise incomes, to improve learning or to reduce illness. Whether these changes are actually achieved is a crucial public policy question but one that is not often examined." GIs, a policy instrument in use for 25 years, have experienced growing interest at the community level, and one of their leading goals is the promotion of rural development. Given these assumptions, one would expect to find a large number of studies investigating whether, how and to what extent GIs actually produced the desired impact in rural areas.

Indeed, a considerable number of case studies have been carried out on the subject. These studies often considered one or a few GIs (usually up to 4), and they were mainly directed at identifying the reasons underlying the success or failure of different initiatives according to several perspectives (economic, social, diffusion among producers). The indicators selected for assessing the evolution of PDO and PGI schemes vary greatly, ranging from the amount of considered production (Barjolle and Thevenod-Mottet, 2002), distinct product features (Barjolle and Sylvander, 2002), number and typology of producers (Barjolle and Thevenod-Mottet, 2002; Tregear et al., 2007; Belletti et al., 2014) to the analysis of GIs' product specifications and their history (Tregear et al., 2007; Quiñones-Ruiz et al., 2016). According to these studies several successful experiences can be found across Europe, showing that implementing a GI product can be a feasible and profitable choice when certain conditions are met. Identifying these factors is

${ }^{2}$ NUTS stands for "Nomenclature of Territorial Units for Statistics". According to EUROSTAT the NUTS classification is a hierarchical system for dividing up the territory of the EU for statistical purposes. of crucial importance for farmers and communities who are willing to differentiate local production using an European indication of origin. This stream of literature either suggests best practices or provides insights into whether and how GIs may be successful.

The main drawback of these studies, when considered from an impact evaluation perspective, is that they rarely offer a precise and externally valid quantitative assessment of the effectiveness of GIs (to what extent they reach a given objective). When searching for such an assessment only scant literature can be found. The most frequent variable considered when examining the impact of GIs is the price premium they generate over the benchmark price. There is considerable evidence that GI products usually have a higher price in comparison with the average price of standard products (Folkeson, 2005) providing the producer with a higher value (Chever et al., 2012). This underlines the consumer awareness of food quality attributes, although across different European countries there are changes in the price differential. The price premium also varies across retail outlets, for example, it is lower for larger retailers (Schröck, 2014). However, the presence of a price premium at the market level does not imply an effective impact on rural development. According to Callois (2006), highly differentiated products, such as GI products, tend to favour small specific groups of actors that are able to capture very high rent and the beneficial effects may not be shared with the local community. A more effective way to measure the impact of such certification is to select and analyse local indexes and to compare their values between areas where GIs are and are not implemented. The few available studies developing such an approach show positive impacts. Research conducted by De Roest and Menghi (2000) shows how Parmigiano Reggiano triggers the employment along the food chain with respect to other similar products. Bouamra-Mechemache and Chaaban (2010) extend this finding to the entire French cheese sector where the employment effect, at both the industry and farm level, seems to be due to an increase in the number of firms working along the GI supply chain. Positive effects on both employment and value added were found by Coutre-Picart (1999) who studied the AOC (the French pre-existing scheme equivalent of the European PDO) Savoy cheese sector. Another relevant study examining the local effects of GIs, although addressing mainly environmental issues, is that conducted by Hirczak and Mollard (2004), who compared the spatial distribution of the density of GI labels and several ecological indexes.

All these studies address the quantitative evaluation of the impact of a single certified product on a specific limited area; the literature does not provide insight into the effect of the overall policy at the EU or country level. We aim to fill this gap in the literature by providing a quantitative study of the impact of Italian GIs on agricultural value added in rural areas. To our knowledge, this is the first attempt to provide such an overall quantitative assessment.

We selected Italy as a case study, being the country with the highest number of GI registered products. We first designed an index to reduce the complexity of the policy tool (number of GIs, protected area, type of product concerned, age of the GIs) to a single dimension. Although statistical techniques such as multivariate analysis are able to cope with multiple dimensions, to keep things simple we opted for a summary index. Apart from the paper by Hirczak and Mollard (2004), the index has not previously been used to assess the impact of GIs on rural development. We choose as the index the number of GIs registered in the NUTS3 region weighted by the area of the municipalities interested in the GIs. Then, we devised a logical model to describe the pathways through which the implementation of GIs leads to higher rural development. Agricultural value added per hectare was chosen as outcome variable since it is one of the most common indicators of rural development (World Bank, 2000) and it is easily available at the NUTS3 level across EU countries. We kept the model as simple as possible to assess the impact of GI policy on the local agricultural value added drawing on consolidated methods in policy impact analysis.

In the next section, the data employed in the analysis are described 
with a specific focus on the index building process and its distribution in the Italian territory. We then illustrate our impact assessment strategy and its econometric specification.

\section{Materials and methods}

In the first stage of the work a specific index was built to represent the intensity of protection through GIs implementation in NUTS3 regions. In doing so, information on Italian GI products was retrieved from DOOR, a database containing basic information on each European geographical indication, such as the type of protection ${ }^{3}$ and the year of registration, along with the product specification. Moreover, data on municipal and provincial areas, as well as spatial data (shapefiles), were collected from the Italian Institute of Statistics (ISTAT) web site for the period covered by the study (2000 and 2010).

The second part of the work addressed the impact assessment issue using a difference-in-difference design implemented with a fixed-effect econometric model. Data needed for the construction of variables (other than the index) included in the regression model (see paragraph 2.2) were retrieved from the ISTAT website and ISTAT Agricultural Census databases, also available on line.

\subsection{Intensity of protection index}

In Italy, geographical indications are often associated with high variability, in terms of both product type (oil, cured meat, vegetables) and the size of the territories covered by the indication. For instance, the "Agnello del Centro Italia IGP" can be produced in 6 different regions while the "Fagiolo di Sorana IGP" has an authorized grown area of nearly 660 ha, with less than 80 quintals of production in 2012 (Belletti et al., 2014).

This consideration led us to discard the hypothesis of using the simple number of GI products per province ${ }^{4}$ (i.e., NUTS3 regions) as a valuable indicator of the extent of protection of geographical indications in each territory and to build an index to consider also the size of the entire protected area, according to the product specification, allowing us to consider the GIs' importance in the sector.

We also decided, due to the peculiarities of the sector, not to include wines in the analysis. Indeed, protection of geographical indications for wines in Italy dates back to the 1960s (D.P.R. 12 luglio 1963, n.930: "Norme per la tutela delle denominazioni di origine dei mosti e dei vini"), but we lack the temporal variability of a protection intensity index needed to estimate the impact on rural development in the last decades.

We attempted to formalize the type of geographical analysis carried out by Hirczak and Mollard (2004) $)^{5}$ by computing a summary measure of the intensity (or density) with which the GI policy has been implemented in a province.

The index, was computed according to the following formula:

$P I I_{i, t}=\frac{\sum_{m}\left(n_{m, t}^{*} A_{m, t}\right)}{A_{i, t}}$

where $n_{m}$ is the number of GIs per municipality, $A_{m}$ is the municipality area and $A_{i}$ is the province area. The subscript $t$ indicates the year

\footnotetext{
${ }^{3}$ The EU legal framework (Regulation (EEC) 2081/92 and Regulation (EU) 510/2006) identifies three different types of Geographical Indications: PDO (protected designation of origin) requires the entire production process to be implemented in the area of origin; a PGI (protected geographical indication) can be attached to a product when at least one phase of the production process is located in the concerned area; and TSG (traditional specialities guaranteed) does not guarantee a link with a specific geographical area certifying only production methods.

${ }^{4}$ Italy is administratively divided in provinces corresponding to the EU NUTS3 territorial disaggregation.

${ }^{5}$ Hirczak and Mollard (2004) produced thematic maps on which the number of AOCs per municipality, a measure of density of protection, was plotted and compared to thematic maps concerning environmental indicators to identifying whether any overlapping occurred.
}

the index refers to. Thus the index can be considered as a weighted sum of counts of GIs per province or NUTS3 area.

Table 1 summarises some statistics of the index distribution in the years of analysis, i.e. 1998 and $2008,{ }^{6}$ as well as of the difference in the two years values. Fig. 1 approximates the three variables' distributions using density histograms.

As expected, the average value of the index increased over time. While new applications are presented, old denominations are usually not withdrawn. Data also show an increase in variability, leading to higher dispersion of the distribution in 2008. The observed results concerning the increase over time of both the index mean and variability are confirmed when the entire panel is considered, instead of two years only (Fig. 2).

The average increase in the index values in the 1998-2008 period was 1.92 . Nearly $70 \%$ of the provinces are in between the increase range 1-2.5 points, but there are several areas (around 15\%) showing an increase equal or approximately equal to 4 points. The geographical distribution of these features will be analysed in the results section.

\subsection{Impact analysis}

As a part of the impact analysis, we set out a theoretical framework, presented in Section 3.2.1, to select the econometric model best suited to measure the impact.

\subsubsection{Theoretical model}

The hypothesized causal structure between the GI policy and local rural development was modelled using a "directed acyclic graph" (DAG). DAGs are diagrams originally developed in the epidemiology field to make clear the causality pattern characterizing the study framework in which a researcher works. Causal relationships among variables are represented by directed paths according to the researcher's prior beliefs and hypothesis. Graphs "provide a direct and powerful way of thinking about causal systems of variables and the identification strategies that can be pursued to estimate the effects within them" (Morgan and Winship, 2008, p. 62). DAGs can thus be considered useful instruments to fully understand the logic of a causal relationship and to take important decisions about which covariates should be included in an econometric model and which confounding factors are in place (Glymour, 2006).

In Fig. 3, the DAG shows our causal assumptions. Our interest relies on estimating the direct effect of the GI policy on regional rural development (measured through the value added per hectare). However, we posit that this relationship is confounded by other local specific variables implicated in the dimension of both the policy and the outcome variable. As noted in the introduction section, Lee and Rund (2003) and Parrot et al. (2002) suggest different causes for the observed differences in GIs usage throughout Europe, i.e., climatic and socioeconomic factors. We hypothesized that also at NUTS3 level these two clusters of variables may influence the implementation of GIs. Based on this reasoning we grouped them into a single region-specific variable (named "local conditions" in Fig. 3).

In addition to the direct influence in determining the degree of GI scheme implementation, this variable also affects other relevant characteristics, which in turn are connected to GI usage at the local level. Among these characteristics, social capital is assumed to have primary importance, given its influence on the capacity of local communities to bring about the geographical indication protection process, which requires a collective effort of local actors (Quiñones-Ruiz et al., 2016). At the same time marginal areas, with poor farm types (e.g., hilly or mountainous areas), are the very ones that seek a way out of their marginalization through the GI policy. Thus, areas that are considered

\footnotetext{
${ }^{6}$ As explained later we use sligthly different reference years for the policy (the index) and the outcome (value added) variables.
} 
Table 1

Descriptive statistics of protection intensity index (PII) for 1998, 2008 and 2008-1998.

\begin{tabular}{llll}
\hline Statistic & PII 1998 & PII 2008 & PII 2008-PII 1998 \\
\hline Minimum & 0.74 & 1.00 & 0.00 \\
Maximum & 6.27 & 10.27 & 6.00 \\
Mean & 3.05 & 4.97 & 1.92 \\
Standard deviation & 1.55 & 2.55 & 1.48 \\
\hline
\end{tabular}

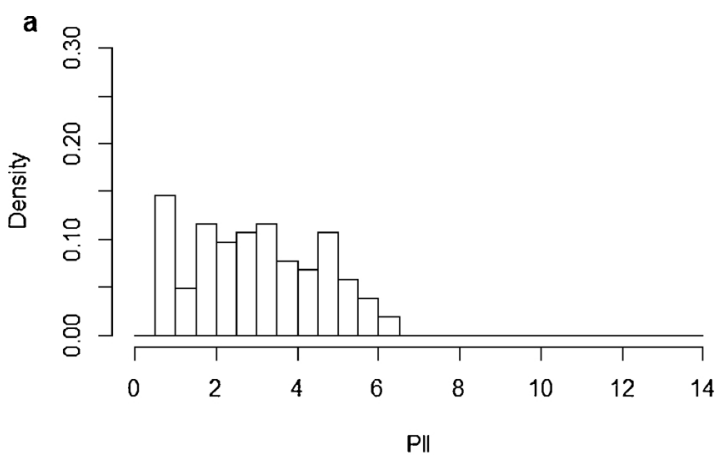

$\mathrm{P \|}$ short period of a decade.

We acknowledge that the model is a simple one. Indeed, the literature on GIs has shown rather complicated mechanisms through which this instrument can affect rural development, through both direct and indirect ways. Therefore, other paths leading from GI adoption to rural development can be identified and studied, though the collection of the necessary data could be difficult and not always successful. Moreover, the time invariance of several local factors, both natural and socio-economic ones, could be considered too strong a condition to

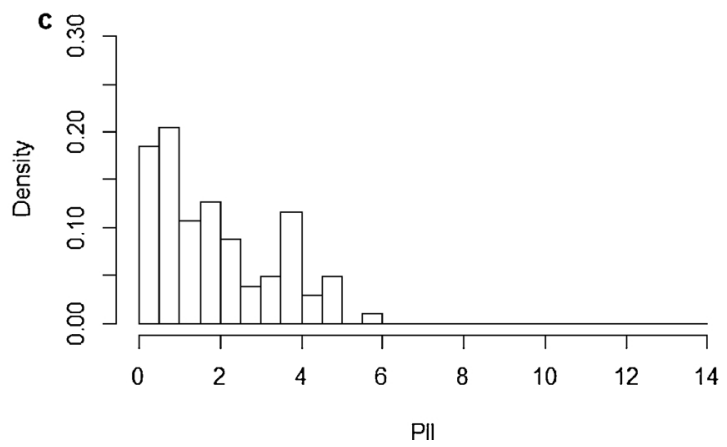

Fig 1. Density distributions of protection intensity index for 1998 (a), 2008 (b) and 2008-1998 (c).

marginal according to the productivist paradigm (Van Der Ploeg et al., 2000), find a way to pursue a different development trajectory based on the GI policy. Therefore, we expect social capital rich but agriculturally poor areas to be characterized by both high levels of GI scheme implementation and lower rural development indicators values.

On the other hand, agronomic, pedoclimatic and social conditions contribute in determining the prevalent farm types in the area and consequently their labour intensity, which in turn is a factor connected to rural development as measured by value added per hectare.

Because of all the posited causal relationships, measuring the desired impact of the GI policy on the outcome variable requires the conditioning on confounding factors. However, for some of these factors, notably social capital and pedoclimatic conditions, there are no available published data that are easy to retrieve. Nevertheless, if we could condition on the idiosyncratic local characteristics of each province, we would overcome the measurement problems for other variables such as social capital. To this purpose we exploit the panel nature of our data and specify a fixed effect model. Noticeably, we can assume that fixed effects are realizations of a qualitative variable related to time invariant idiosyncratic local conditions. Indeed, both social capital and pedoclimatic factors can be considered as time invariant. Natural elements changes slowly and need a very long time to produce significant effects on the agricultural structure (farm types) of a certain region. Following Putnam (1993, p. 163ö185) social capital is assumed as a permanent element that characterizes each society and is created by a cumulative process through centuries. Thus, even this variable experiences only long-term changes and is invariable in the relatively

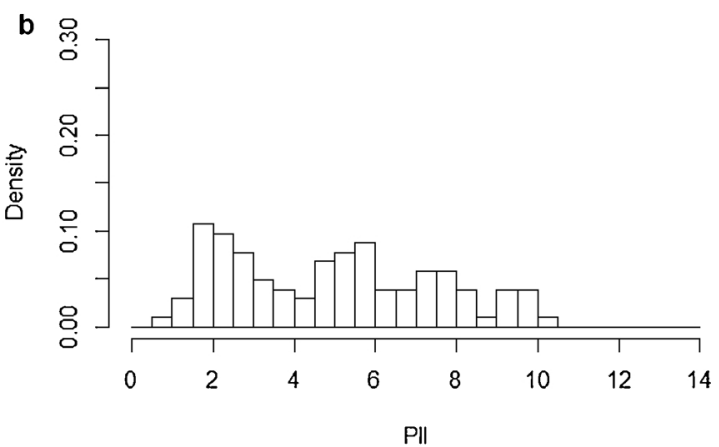

PII maintain over a 10 years period. The rejection of such a hypothesis would result in the need for extensive data on climatic, geographical, social and economic variables. Indeed if these factors do not remain constant over time, we need to explicitly include them in the econometric model (see Section 3.2.2) and estimate their contribution in determining the outcome value. Although these considerations would be useful and valuable in advancing the evaluation of the GI policy, we believe that, especially in this first tentative evaluation, it is worth identifying the "stylized facts" underpinning such mechanisms to ensure the feasibility of any overall quantitative analysis of the impact of the GI policy at the country level.

\subsubsection{Impact analysis}

Given the above discussion, we turn back to the framework presented in the previous paragraph to specify the econometric model. According to the back door criterion stated by Pearl et al. (2016, p. 61), it is sufficient to condition on a variable representing time invariant local conditions for each province to identify the effect of the index of GI protection on agricultural value added per hectare. Indeed, referring to the DAG, the local conditioning variable blocks every additional path (sequence of nodes and arrows connecting them) from the outcome to the intervention variable. From an econometric point of view, this can be obtained by exploiting the panel nature of our dataset and estimating a fixed effect model. In addition, the availability of repeated observations for both the intervention and outcome variable allows us to implement a difference-in-difference (DD) impact estimation strategy. In its simplest form and with a binary intervention variable, the DD 
a

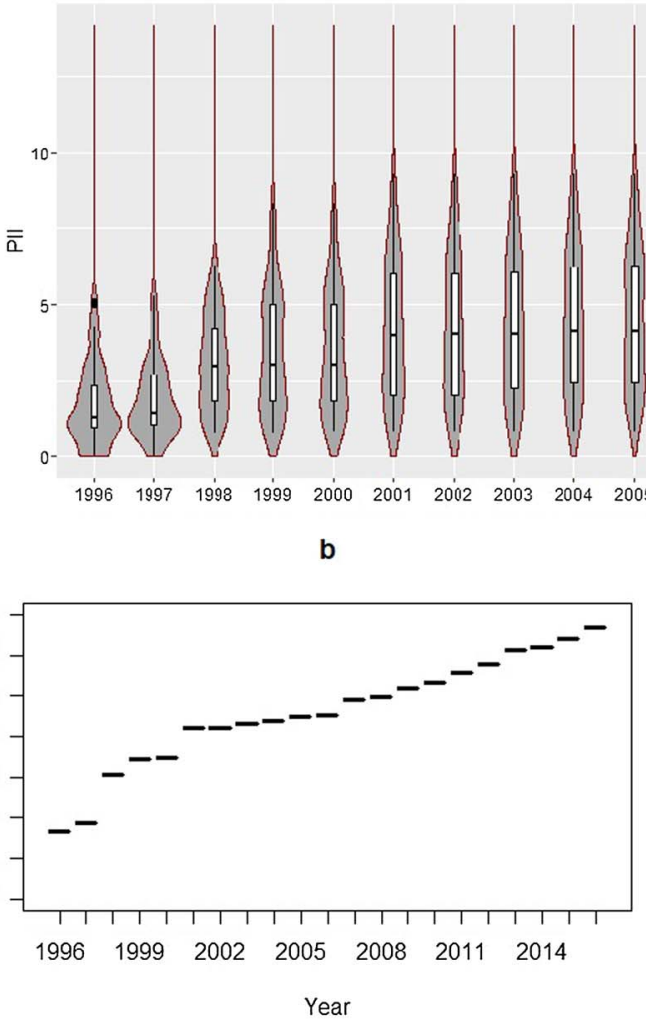

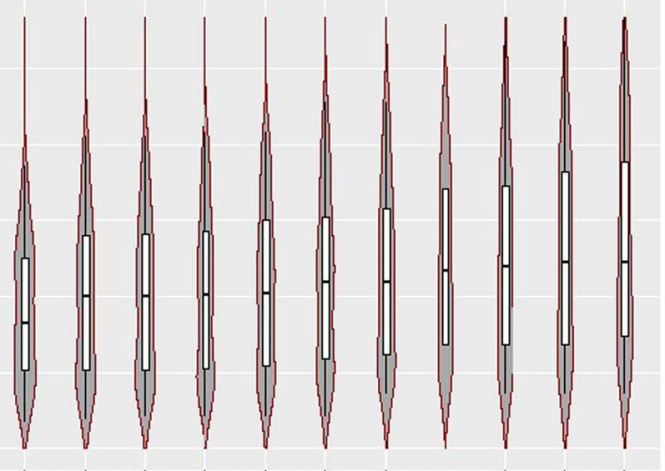

Year

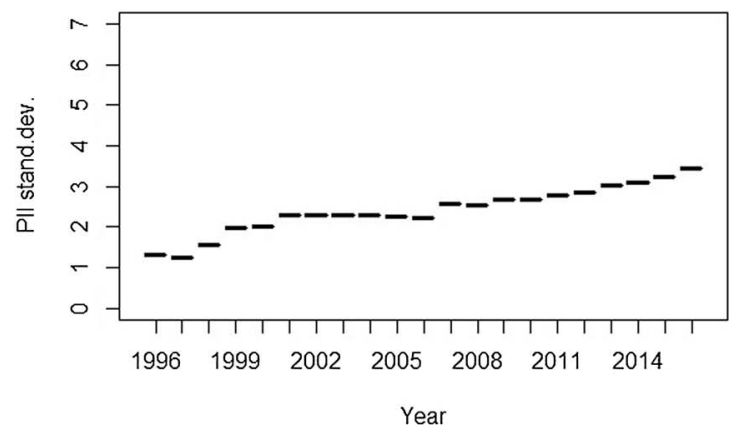

Fig. 2. Trend over time of provincial index values (a), and national index means and standard deviations (b,c).

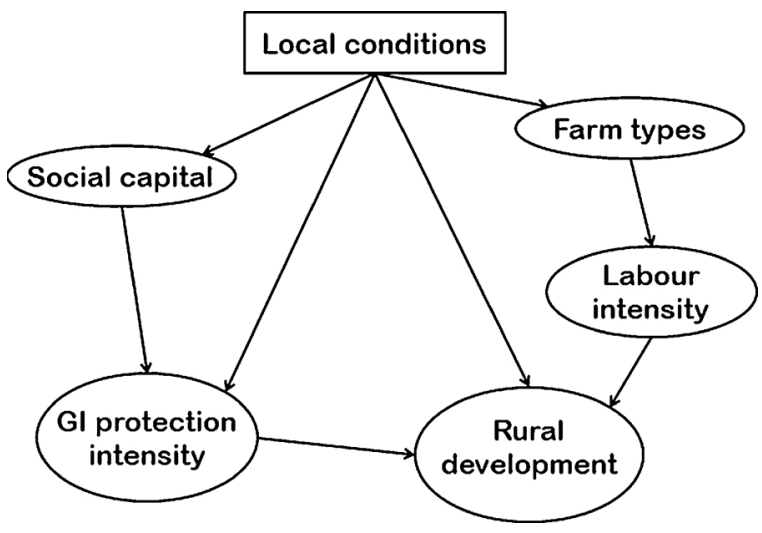

Fig. 3. Hypothesised logic model.

Table 2

Summary statistics of main variables.

\begin{tabular}{|c|c|c|c|c|c|c|}
\hline & \multicolumn{3}{|l|}{2000} & \multicolumn{3}{|l|}{2010} \\
\hline & $\begin{array}{l}\text { AVA/UAA } \\
(x 1000 € / h a)\end{array}$ & $\begin{array}{l}\text { WU/ } \\
\text { UAA } \\
\text { (wu/ } \\
\text { ha) }\end{array}$ & $\mathrm{PII}_{98}$ & $\begin{array}{l}\text { VA/UAA } \\
\text { (x1000€/ } \\
\text { ha) }\end{array}$ & $\begin{array}{l}\text { WU/ } \\
\text { UAA } \\
\text { (wu/ } \\
\text { ha) }\end{array}$ & $\mathrm{PII}_{08}$ \\
\hline Mean & 3.07 & 0.10 & 3.05 & 3.16 & 0.11 & 4.97 \\
\hline $\begin{array}{l}\text { Standard } \\
\text { deviation }\end{array}$ & 2.51 & 0.08 & 1.55 & 3.70 & 0.12 & 2.55 \\
\hline Min & 0.49 & 0.01 & 0.74 & 0.33 & 0.01 & 1.00 \\
\hline Max & 14.57 & 0.15 & 6.27 & 25.29 & 1.15 & 10.27 \\
\hline
\end{tabular}

method estimates the difference in the outcome after the intervention between a treatment group and a comparison group relative to the outcomes observed before the intervention (Shahidur et al., 2010). The econometric specification for the DD is given by:

$Y_{i, t}=\alpha_{i}+\delta T_{i, t} t+\rho T_{i, t}+\gamma t+\sum \beta X_{i, t}+u_{i, t}$

where $Y$ is the outcome, $\alpha_{i}$ is an individual specific intercept, $T$ is the intervention variable, $t$ is a time dummy, $X$ represents other independent variables, and $u$ is an i.i.d. $\left(0, \sigma_{\mathrm{u}}\right)$ error term. The subscripts in the equation represent the single unit of analysis $i$ and the year of observation $t$. Independently of the chosen fixed effect estimator, the parameters of the model are equivalent to those obtained by inserting a dummy variable for each province in the equation ${ }^{7}$ (Wooldridge, 2013).

In the classical DD model with a treatment dummy assuming values 1 for the treatment group and 0 for the control, the $\delta$ parameter, associated with the interaction term between the treatment $T$ and the time dummy variable $t$, identifies the expected impact.

In our case the estimator assumes a different meaning as we are dealing with a continuous treatment variable (the protection intensity index), not a binary one. It can be demonstrated that in the case for the $\mathrm{i}^{\text {th }}$ individual (province) the $\delta$ parameter is equivalent to:

$\delta=\frac{E\left(Y_{i 1-} Y_{i 0} \mid T_{i}=T_{i 1}\right)-E\left(Y_{i 1-} Y_{i 0} \mid T_{i}=T_{i 0}\right)}{T_{i 1}-T_{i 0}}$

The numerator is given by the expected difference in the temporal outcome variation given the final and initial values of the continuous intervention variable; the denominator is given by the difference between the final and initial values of the continuous treatment variable. In summary, when we observe an increase in the continuous treatment variable between the two periods, a positive value of $\delta$ indicates that

\footnotetext{
${ }^{7}$ This, in turn can be considered as a parameterization of a qualitative variable that assumes different values for each province, i.e., the time-invariant local conditions variable described in the casual model.
} 


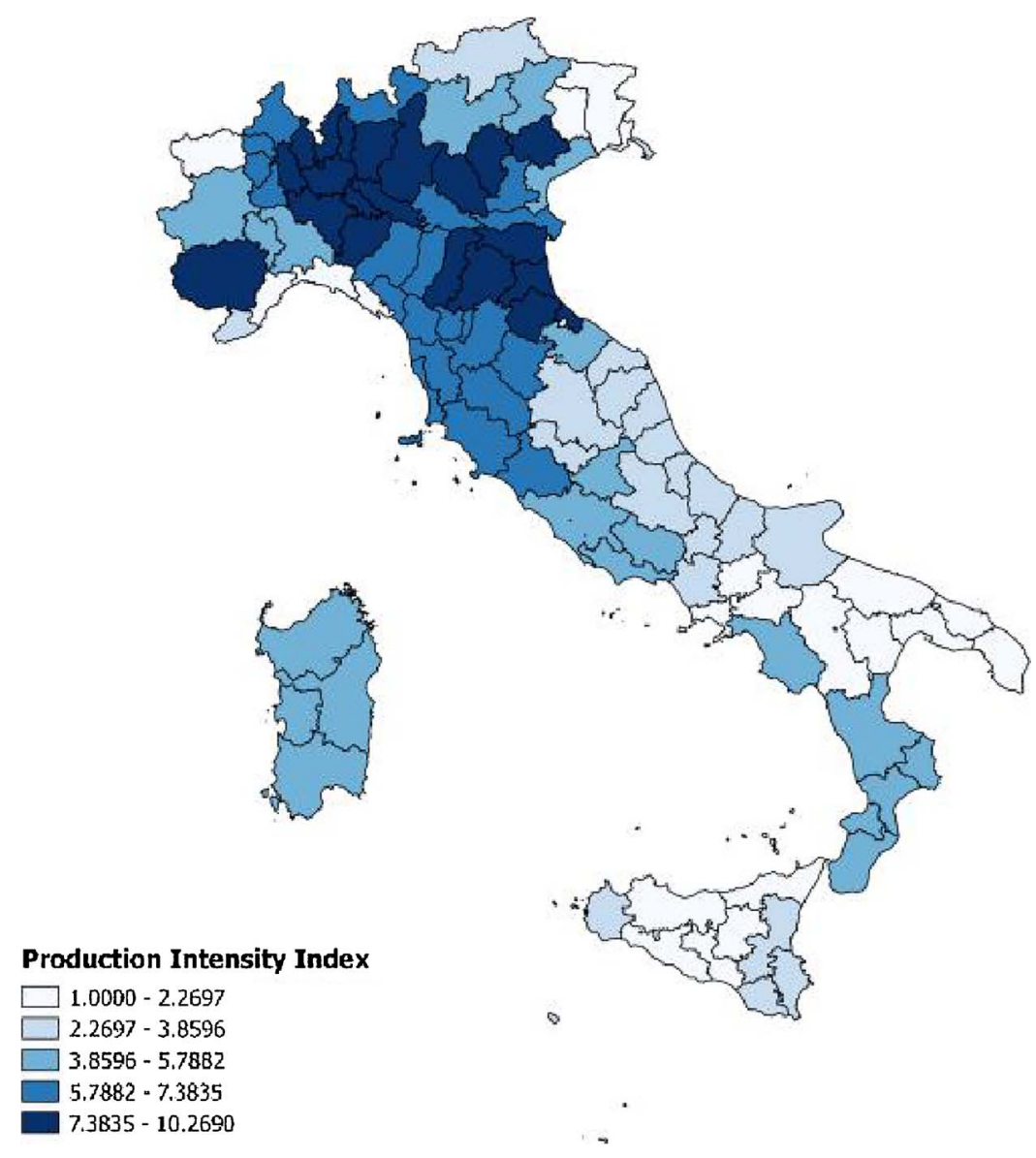

Fig. 4. Protection intensity index distribution in Italy, 2008.

the increased intensity of treatment causes a larger increase in the outcome variable, that is, the impact of the treatment is positive. ${ }^{8}$

The variables to be included in Eq. (1) were selected according to the theoretical model depicted in Fig. 3. The outcome variable $\left(Y_{i, t}\right)$ is the agricultural value added (AVA), measured at current prices, per hectare of utilized agricultural area (UAA), ${ }^{9}$ representing a common indicator for rural development. Since we are interested in determining the effect of the implementation of GI schemes, the protection intensity index is considered as the treatment variable in the model, that is $T$ in Eq. (1). The only covariate $(X)$ included in the model, according to the theoretical explanations given in the previous section, is the working units (WU) per hectare of UAA variable. Finally the subscripts, determining the spatial and time levels at which the analysis is carried out, represent the Italian NUTS3 regions ( $i$ ) and the census years 2000 and $2010(t)$. With respect to the time span, it is worth noticing that during this period some changes occurred in the administrative setting of Italy since several new provinces were created. We thus decided to work with the 2000 administrative setting since translating the newer data in a more aggregate framework is a far easier operation than disaggregating old data for once larger provinces.

A further clarification has to be added with respect to the index values included in the model. The index variable does not refer to the years of analysis, but to two years before, i.e., 1998 and 2008. Indeed, we assume that the likely effect of a protection scheme implementation

\footnotetext{
${ }^{8}$ See Acemoglu et al. (2004) for a similar application of the difference in difference method with a continuous treatment variable.

${ }^{9}$ We acknowledge that the results of the DD model depends on the scale of measurement of the outcome variable (Lechner, 2010). Since we are interested in the linear relationship between the weighted sum of count of GIs per province and agricultural value added per hectare, we maintained a linear parameterisation.
}

on economic variables is somewhat lagged, as a new GI needs time to become fully operational. Furthermore, a lagged policy variable can contribute to mitigate possible residual endogeneity problems arising from other common causes affecting both the index and the value added. The choice of a two years lag instead of three or four years lags is due to the peculiarity of the implementation of the policy in its starting years. The first three years (1996-1998) were entirely dedicated to the integration of pre-existent national GIs into the new European policy framework, while completely new denominations were registered only from 1999 onwards. So, if we consider the periods 1996-2006 and 1997-2007, a quite large share of the difference in the number of GIs (respectively, $40 \%$ and $20 \%$ ) is due to the integration procedure. The integrated products were already known by consumers and sold in both national (and also international) markets. Consequently, their registration increases the number of registered GIs but possibly has only small effects on modifying economic indicators.

\section{Results}

\subsection{Comparison of variables geographical distribution}

Table 2 summarizes the main statistics for the variables included in the model for both years considered in the analysis.

The index and AVA/UAA quantile distributions across the Italian peninsula are reported in Figs. 4 and 5.

A remarkable feature emerging from the index figures is that there is no province without at least one registered GI product. As for many other phenomena in Italy, a divide emerges between the CentralNorthern and the Southern regions. The highest values are observed mainly in the Padan Plain area, in Lombardy and along the uppercentral Tyrrhenian coast, namely, in Tuscany and in Lazio, but on 


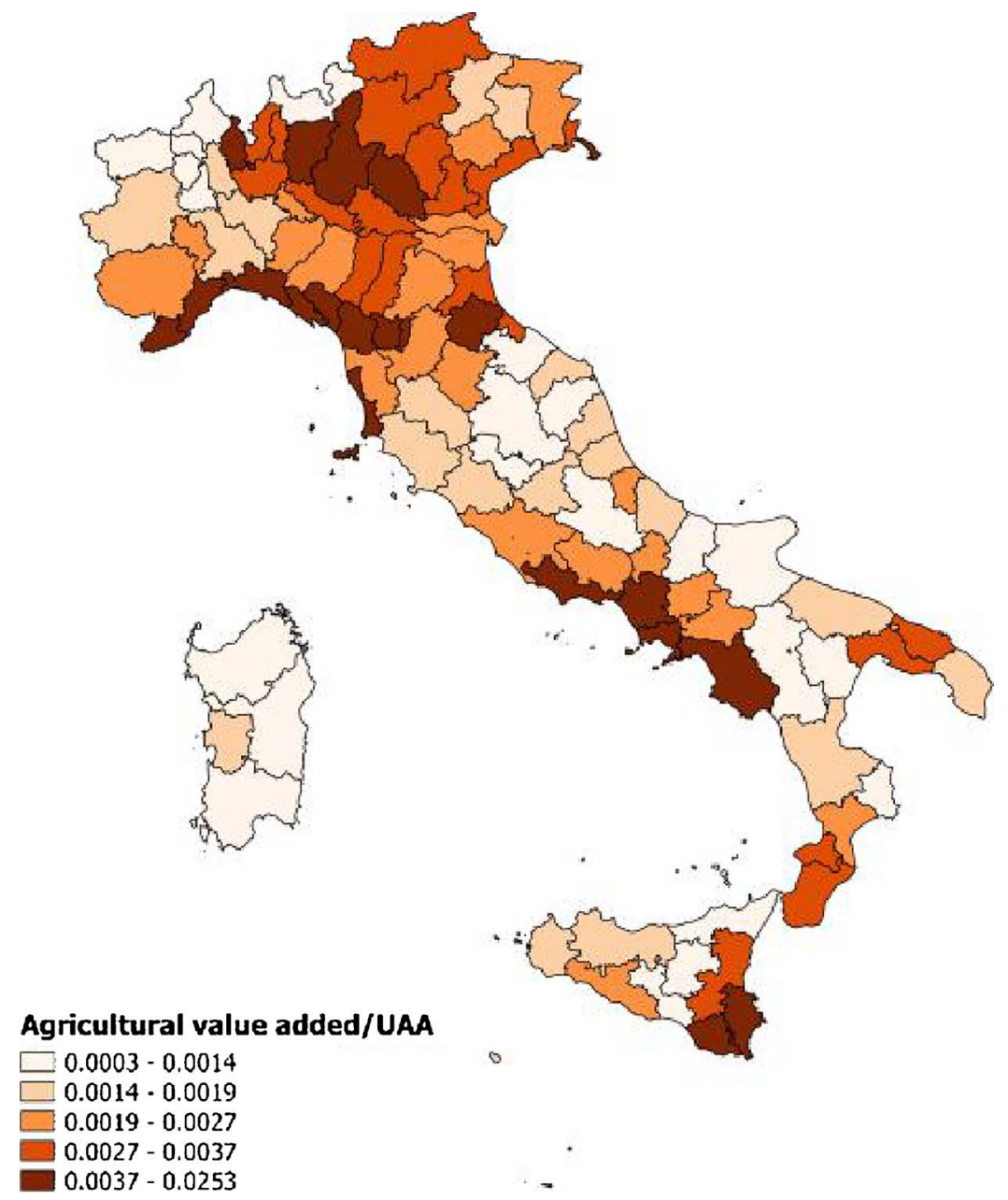

Fig. 5. Agricultural value added per hectare in Italy, 2010.

average in the North of the country a higher concentration of GI schemes is observed. Despite this general pattern, some exceptions can be detected, such as the entire Liguria and Friuli Venezia-Giulia regions which occur in the lowest quantile.

The economic index (AVA/UAA) shows a rather different pattern, although a North-South divide is again observed, with Northern and Central provinces showing higher values than Southern ones. It is worth noticing the presence of some provinces in the South placed in the first two quintiles of the distribution, such as Lazio and Campania coastal provinces, the Sicily South-Eastern area, the lowest part of Calabria and the Brindisi and Taranto provinces in Puglia.

A first comparison of the two maps reveals that, although some provinces are placed in similar classes in both distributions, there is no general accordance between the two indicators. Conversely, several provinces show quite different ranking positions between the two distributions. This is the case for the entire Liguria Region where the highest values of AVA/UAA are observed but where the PII is among the lowest in Italy. The opposite situation, although less frequent, is observed in Sardinia and in a few other provinces throughout peninsular Italy.

This visual examination led us to conjecture that the spatial similarities between the index and AVA/UAA are mainly linked to the classic Italian North-South divide, becoming less evident when the analysis focuses on a more detailed level. This is also confirmed by a negative correlation index between the two variables. We hypothesized this to be an effect of a self-selection bias since GI policy instruments might be voluntarily adopted by local food chain actors in less favoured areas to pursue an alternative development strategy (see Section 3.2.1).
As long as our assumption about the time invariance of the local characteristics which affect both the adoption of GIs and the agricultural value added is valid, our estimation strategy based on a fixed effect parametric DD equation should deal with the self-selection issue.

The above discussion provides an understanding of the status quo of the two variables. Nevertheless, our interest relies mainly on how such variables change over time. Before approaching the econometric model addressing this issue, we deem it helpful to first provide a visual representation. In Figs. 6 and 7 the changes in the two variable values over the observed 10 years period are shown using a quantile distribution.

In Fig. 6 we can observe that the highest increase in the index value merges almost exactly with the Padan plain area, affecting mainly Lombardy and Emilia-Romagna provinces. On the other hand, these NUTS3 regions are not those experiencing the best change in agricultural value added per hectare. Rather, the North-Eastern provinces are the most affected areas, based on a general decrease in the economic indicator values. Conversely, in Southern regions, which show almost no variance in the degree of protection through GI schemes (except Sardinia), several provinces can be identified increasing their AVA/ha (or only slightly decreasing it).

A comparison of the patterns shown in the above thematic maps leads us to conjecture that no positive correlation exists between the index and the rural development indicator and that, if a relationship has to be traced, it is likely a negative one. However, because several factors play a role in determining the economic status (and changes) of a territory, a direct comparison of Figs. 6 and 7 would be misleading. The aim of the following analysis is precisely to take into account such other 


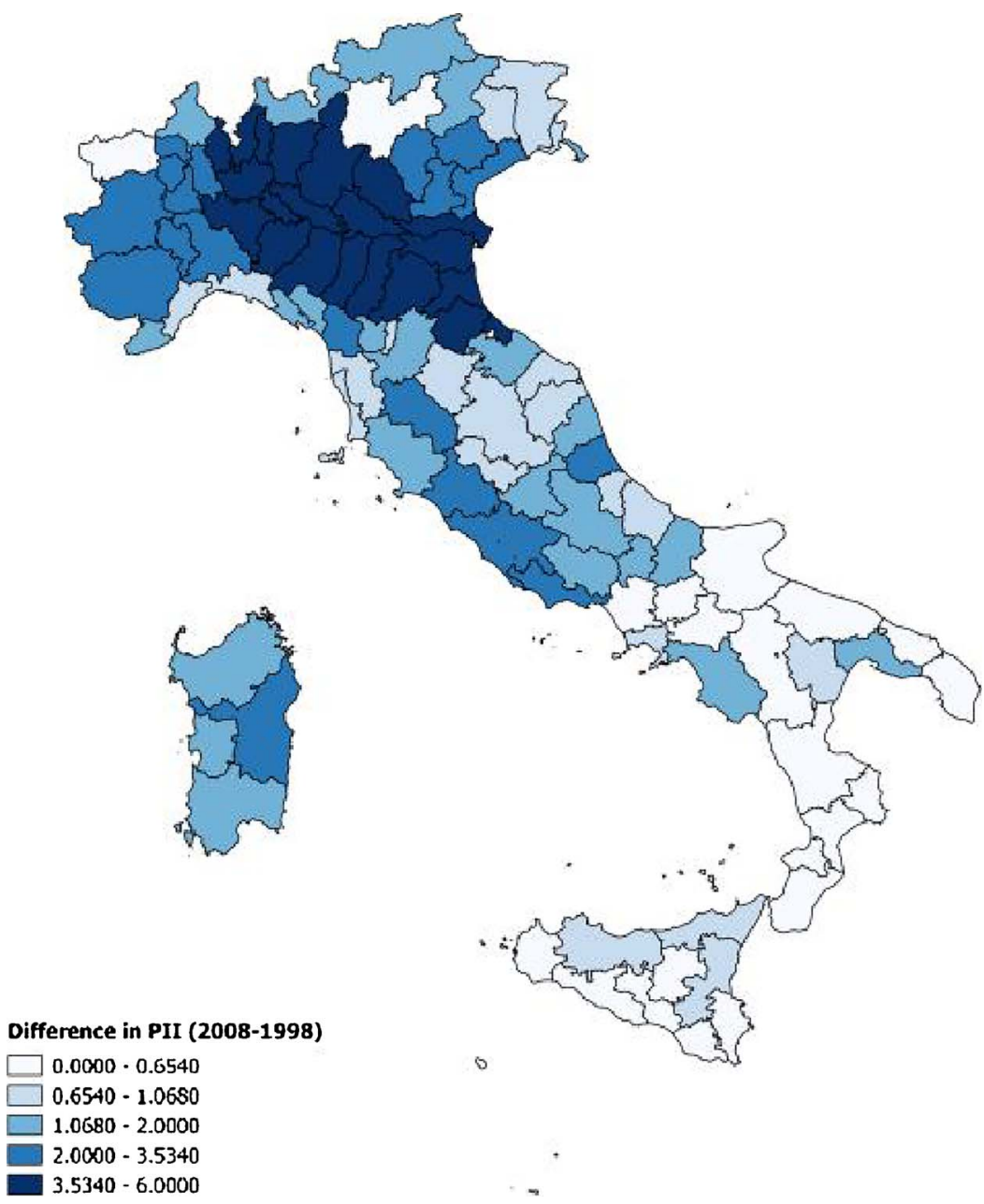

Fig. 6. Distribution of the difference in PII values in Italy in the 1998-2008 period.

factors to isolate the cause-effect relationship between the two considered variables.

\subsection{The econometric model}

To estimate the impact of the density of GIs on the agricultural value added according to the causal model described in Section 3.2.1 we set up a fixed effect econometric model that exploits the available panel dataset. The single intercepts, one for each Italian NUTS3 region, can be considered a "measure" of the overall effect of time invariant factors affecting both the policy variable and the indicator of rural development (the outcome).

The results of the fixed-effect regression model are reported in Table 3. It has to be noted that these results are not invariable to monotone transformations, so they hold only for the selected linear parameterisation.

As both the independent and dependent variables show some sign of spatial pattern such as the North-South divide discussed in the previous section, we also wanted to test the occurrence of interference effects between different units. To do this, we checked for the presence of spatial correlation among regression residuals using Moran's I statistic (Arbia, 2014). We computed the statistic separately for the 2000 and 2010 residuals. For both years, no evidence of spatial correlation was observed, as shown in Table 4.

As expected, the occupational variable, which in our model relates to the different farm types, has a positive and very significant coefficient in the agricultural value added per hectare regression and the common intercept coefficient is significant and positive. The fixed effect estimator also allows us to compute the specific province intercepts, whose values are graphically shown in Fig. 8, while regional (NUTS 2) means are reported in Table 5.

Our estimates show that Northern and Central Regions are characterized by higher specific fixed effects. In this sense, the previous analysis concerning the agricultural value added distribution is confirmed, even after controlling for an important determinant of AVA/ UAA, such as agricultural work per hectare. All specific time-invariant factors that affect the dependent variable (synthesized in the $\alpha_{i}$ parameters) have higher value added from the primary sector in Northern provinces, especially those in Liguria and Lombardia. Another remarkable observation arising from the comparison of Fig. 5 with Fig. 8 is the heavily reduced number, in the latter, of those "isolated provinces" in the South showing high AVA/UAA values. In these cases, the higher figures for agricultural value added are likely due to higher values of agricultural work per hectare, which in turn relates to labourintensive farm types.

Referring back to Table 3, more relevant for our impact assessment exercise are the coefficients associated with the treatment variable and its interaction with the time dummy variable $\left(P I I^{*}\right.$ Year $)$. Both variables are significant at the $5 \%$ level but with different signs; the former is negative, probably as an effect of the already mentioned self-selection bias, whereby marginal areas tend to use GIs as a tool to foster alternative development trajectories. Alternatively, we may suppose that marginal areas are more capable of preserving local agrobiodiversity, a fundamental input in the GI valorisation strategy. On the contrary, the interaction term shows a positive sign. This means that an increase in the protection intensity index value, which is a consequence of a higher 


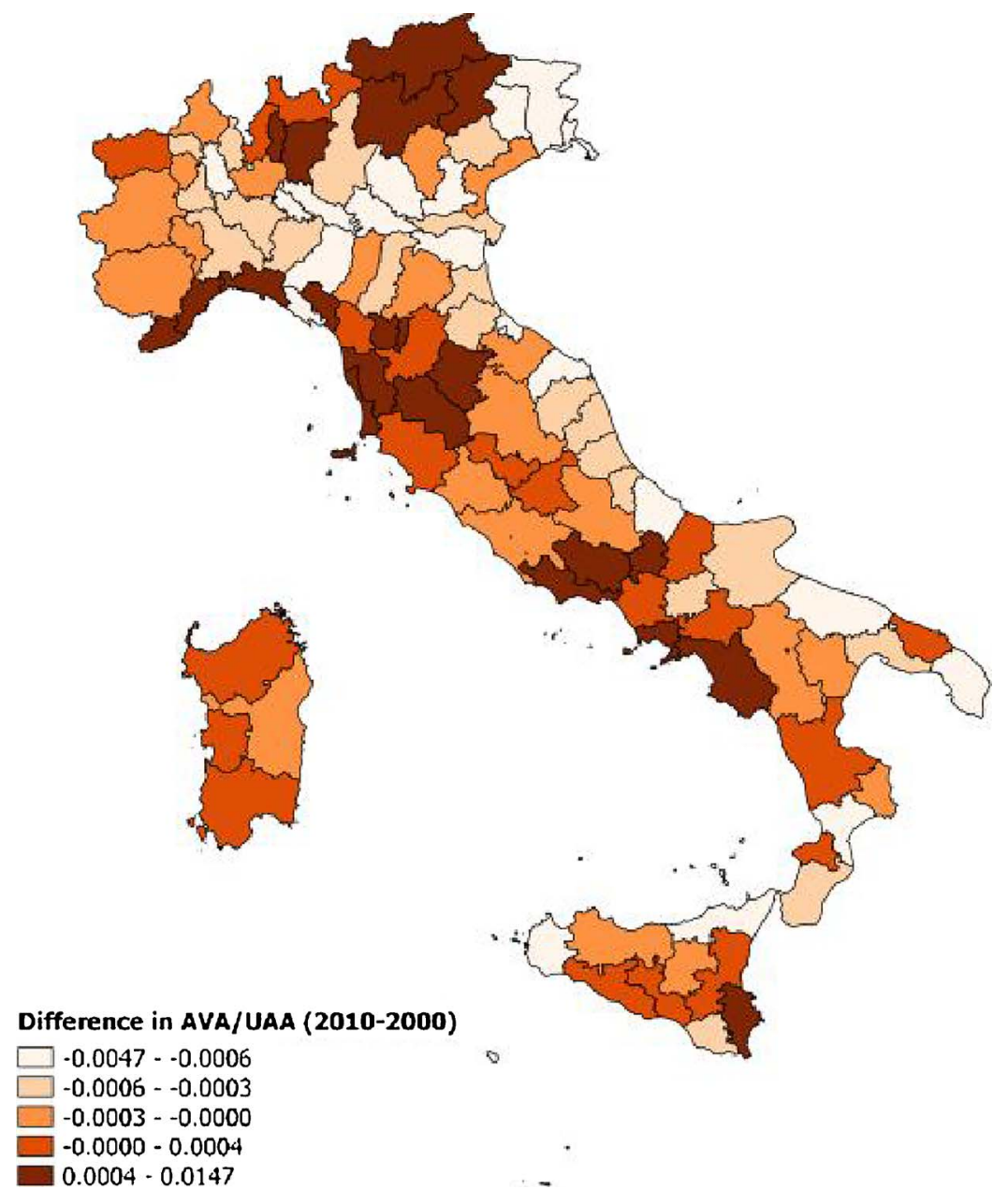

Fig. 7. Distribution of the difference in AVA/hectare in Italy in the 2000-2010 period.

Table 3

Fixed-effect estimates: Dependent variable AVA/UAA.

\begin{tabular}{llll}
\hline & Coefficient & Standard error & p-value \\
\hline WU/ha & 24.16 & 3.71 & 0.000 \\
Index & -0.80 & 0.30 & 0.009 \\
Index*Year & 0.27 & 0.11 & 0.022 \\
Year & -0.48 & 0.37 & 0.197 \\
Intercept & 2.86 & 0.83 & 0.001 \\
\hline & & 103 & \\
$\mathrm{~N}$ (groups) & & 0.426 & \\
$\mathrm{R}^{2}$ & & 0.813 & \\
rho & & $\mathrm{F}(102,99)=7.15 \mathrm{p}=0.000$ \\
$\mathrm{~F}$ test that all $\alpha_{-\mathrm{i}}=0$ & &
\end{tabular}

number of GI schemes (or even of the enlargement of the area covered by the existing schemes), results in local agriculture increasing its value added per unit of UAA at a faster rate, thus possibly fostering rural development in the area.

Table 4

Moran's I statistic computed on regression residuals.

\begin{tabular}{llll}
\hline & I statistic & Standard deviation & $p$-value \\
\hline 2000 & -0.091 & 0.068 & 0.116 \\
2010 & -0.035 & 0.060 & 0.334 \\
\hline
\end{tabular}

\section{Discussion}

GIs are becoming increasingly important in the rural European context, considered in terms of both their number and economic value, fostered by consumer consciousness and a search for quality. Notwithstanding the role this policy instrument has played in the past decades and the "age" of the instrument itself, a total and comprehensive evaluation of its effectiveness still is lacking. Our purpose was to provide a preliminary measurement of the impact the use of GIs has on the territories on which they are applied. We aimed to assess the effects of these products on the agricultural value added per UAA, a common indicator of rural development. Using a specific index and panel data - easily retrievable for other EU countries as well - we were able to implement our impact assessment strategy. On average, if for a given region, the index value had been higher by a one point (for instance, through the implementation of one more GI scheme over the entire provincial area) this would have resulted in an higher (by $270 € /$ ha) increase in the local agricultural value added in the considered period. This is quite an important conclusion because it suggests that this policy instrument has had, at least in the Italian context, a positive effect with respect to one of its primary objectives, i.e., the increase of farmers' income and the fostering of rural development. To our knowledge this is the first attempt to provide such a quantitative measure of the economic impact of the EU policy on GIs at the country level.

Despite this optimistic result, some caveats must be taken into account. First, as previously stated, this is only a first tentative evaluation of the possible effects of GIs on the local economy, based on some 


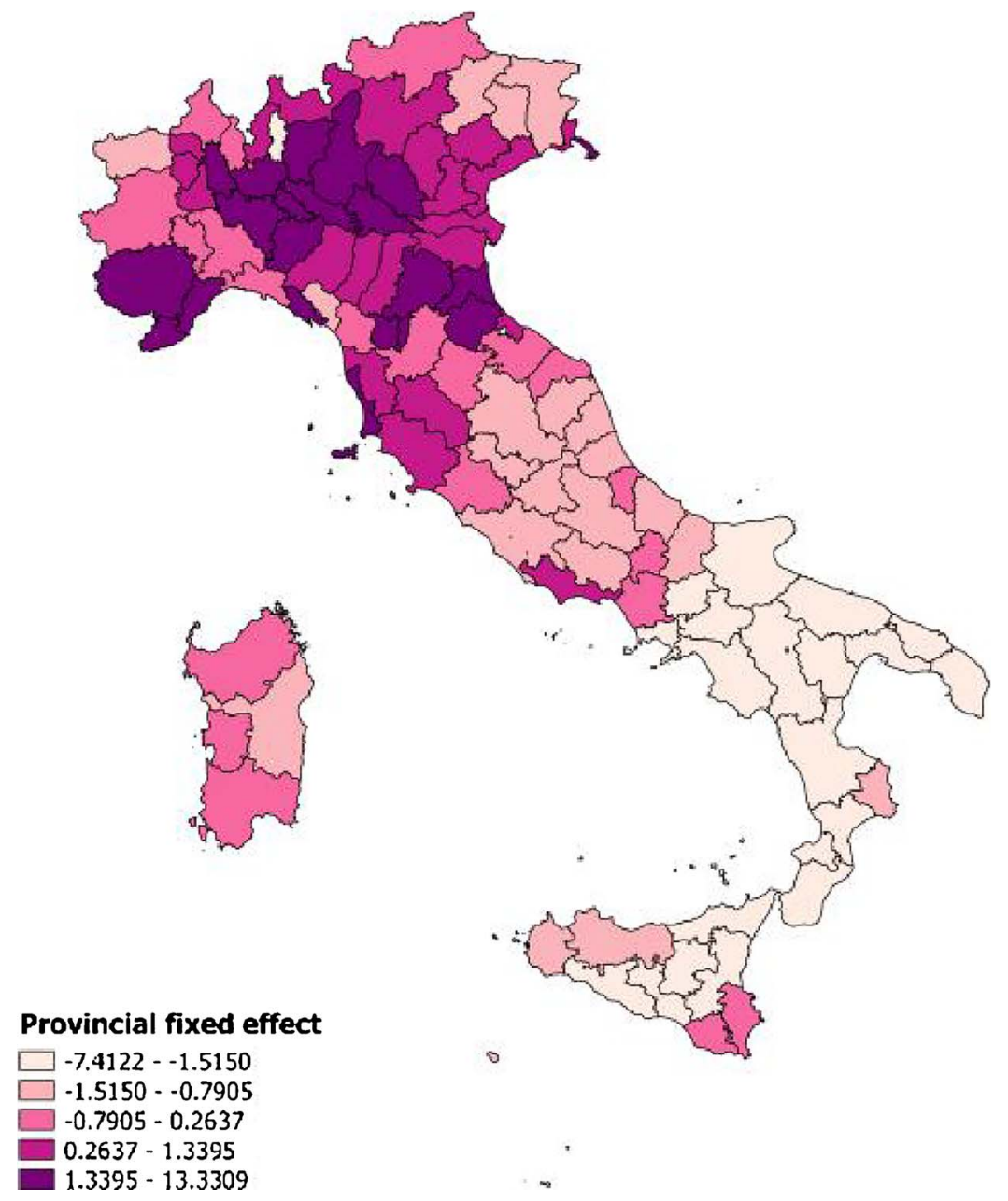

Fig. 8. Distribution of specific provincial fixed effects values.

strong, even plausible, assumptions, such as the time-invariability of many local variables affecting both the policy implementation and the outcome. A second assumption is that underlying the evaluation strategy used. The difference-in-difference method requires the treated and non-treated (in our case less treated) units to show a similar trend when the treatment is not provided. The so-called parallel trend assumption is usually tested using before-treatment data. However, data concerning several variables (utilized agricultural area, agricultural value added, agricultural working units) are not available before 2000, the year our analysis started. Resolving these issues will be possible when the 2020 census results are available and it will provide better

Table 5

Weighted average of regional (NUTS2) fixed effects.

\begin{tabular}{llll}
\hline Re gion (NUTS2) & $\alpha \mathrm{i}$ & Re gion (NUTS2) & $\alpha \mathrm{i}$ \\
\hline Piemonte & 0.66 & Marche & -0.70 \\
Valle d'Aosta & -1.35 & Lazio & -0.71 \\
Lombardia & 1.69 & Abruzzo & -1.09 \\
Trentino-Alto Adige & 0.01 & Molise & -1.07 \\
Veneto & 0.71 & Campania & -2.35 \\
Friuli-Venezia Giulia & -0.69 & Puglia & -2.11 \\
Liguria & 3.07 & Basilicata & -1.66 \\
Emilia Romagna & 1.43 & Calabria & -1.96 \\
Toscana & 0.91 & Sicilia & -1.72 \\
Umbria & -1.11 & Sardegna & -0.63 \\
\hline
\end{tabular}

and more accurate insights into the effectiveness of GI schemes implementation in fostering local rural development.

Several further research lines are opened by this first explorative study. For instance, a more in-depth study of product types is advisable because, depending on their production methods and specific characteristics, they can differently affect various economic sectors such as agriculture, the food industry and even tourism.

A final aspect, as the relatively high amount of literature produced on GIs suggests, has to be kept in mind: the impact we identified has to be considered an overall average effect of the implementation of GI schemes throughout Italy, but it says nothing about the single cases and their possible success. In fact, as reported by Tregear and al. (2007), the implementation of GI products does not assure a positive effect on rural development since local, community and product specific characteristics play a leading role in determining such an effect. It is therefore necessary to continue to study GIs along a double path, on the one hand trying to understand "whether" and "to what extent" they produce the expected results, mainly through quantitative methods, and on the other hand, identifying "how" and "why" they do so, using case studies and other field methods of inquiry. Therefore, this quantitative, country level impact assessment should be considered a useful complement of the case study evidence so far provided for several EU regions and can easily be extended to other countries provided that very simple economic data are available. 


\section{Conflicts of interest}

None.

\section{References}

Acemoglu, D., Autor, D.H., Lyle, D., 2004. Women, war, and wages: the effect of female labor supply on the wage structure at midcentury. J. Polit. Econ. 112 (3), 497-551. http://dx.doi.org/10.3386/w9013.

Arbia, G., 2014. A Primer for Spatial Econometrics. Palgrave MacMillan, UK.

Barjolle, D., Sylvander, B., 2002. Some factors of success for origin labelled products in agri-food supply chains in Europe: market, internal resources and institutions. Économies et Sociétés 25, 1441-1461.

Barjolle, D., Thevenod-Mottet, E., 2002. Ancrage territorial des systèmes de production: le cas des Appelations d'Origine Contrôlée. Colloque SYAL. Montpellier (mimeo).

Belletti, G., Brazzini, A., Marescotti, A., 2014. The effects of the legal protection Geographical indications: PDO/PGIs in Tuscany. In: Aenis, T., Knierim, A., Riecher, M., Ridder, R., Schobert, H., Fischer, H. (Eds.), Farming Systems Facing Global Challenges: Capacities and Strategies. 11th European IFSA Symposium. Berlin, 1-4 April 2014.

Bouamra-Mechemache, Z., Chaaban, J., 2010. Is the protected designation of origin (PDO) policy successful in sustaining rural employment? In: Spatial Dynamics in Agri-Food Systems: Implications for Sustainability and Consumer Welfare, 116th EAAE Seminar. Parma, 27-30 October 2010.

Bramley, C., 2011. A review of the socio-economic impact of geographical indications: considerations for the developing world. In: WIPO Worldwide Symposium on Geographical Indications. Lima, 22-24 June 2011.

Callois, J.M., 2006. Quality labels and rural development: a new economic geography approach. Cahiers d'économie et sociologie rurale 78, 32-51.

Chever, T., Renault, C., Renault, S., Romieu, V., 2012. Value of Production of Agricultural Products and Foodstuffs, Wines and Spirits Protected by a Geographical Indication (GI). Final Report. European Commission, Bruxelles.

Coutre-Picart, L., 1999. Impact économique des filières fromagères AOC savoyard. Revue Purpan 191, 135-153.

De Roest, K., Menghi, A., 2000. Reconsidering traditional food: the production of Parmigiano-Reggiano cheese. Sociologia Ruralis 40 (4), 439-451. http://dx.doi.org/ 10.1111/1467-9523.00159.

European Commission, 2012. Europeans' Attitudes Towards Food Security, Food Quality and the Countryside, Special Eurobarometer. pp. 389.

Folkeson, C., 2005. Geographical Indications and Rural Development in the EU. Master's Degree. Lund University, Lund (Sweden).

Gertler, P.J., Martinez, S., Premand, P., Rawlings, L.B., Vermeersch, C.M., 2011. Impact Evaluation in Practice. The World Bank Washington.

Giovannacci, D., Josling, T., Kerr, W., O'Connor, B., Yeung, M.T., 2009. Guide to Geographical Indication - Linking Products and Their Origins. International Trade Centre, Geneva.

Glymour, M., 2006. Using causal diagrams to understand common problems in Social epidemiology. In: Oakes, J.M., Kaufman, J.S. (Eds.), Methods in Social Epidemiology. Jossey BassSan Francisco.

Hirczak, M., Mollard, A., 2004. Qualité des produits agricoles et de l'environnement: le cas de Rhône-Alpes. Revue d'économie régionale \& urbaine 5, 845-868. http://dx. doi.org/10.3917/reru.045.0845.

Jenkins, T., Parrott, N., 1999. The socio-economic potential for peripheral rural regions of regional imagery and quality products. In: The Socio-Economics of Origin Labelled Products: Spatial, Institutional and Co-ordination Aspects. 67thEAAE Seminar. Le Mans. pp. 128-140.

Landi, C., Stefani, G., 2015. Rent seeking and political economy of geographical indication foods. Agribusiness 31, 543-563.

Lechner, M., 2010. The estimation of casual effects by difference-in difference methods. Found. Trends Econometr. 4 (3), 165-224.

Lee, J., Rund, B., 2003. EU-Protected Geographic Indications: An Analysis of 603 Cases. GIANT Project Report. . https://edspace.american.edu/jlee/giant-project/.

Morgan, S.L., Winship, C., 2008. Counterfactuals and Causal Inference: Methods and Principles for Social Research. Cambridge University Press, New York.

OECD, 2000. Appellations of Origin and Geographical Indications in OECD Member Countries: Economic and Legal Implications. COM/AGR/APM/TD/WP(2000)15/ FINAL.

Parrot, N., Wilson, N., Murdoch, J., 2002. Spatializing quality: regional protection and the alternative geography of food. Eur. Urban Reg. Stud. 3 (9), 241-261. http://dx.doi. org $/ 10.1177 / 0967642002009003878$.

Pearl, J., Glymour, M., Jewell, N.P., 2016. Causal Inference In Statistics. A Primer. Wiley Chichester.

Putnam, R.D., 1993. Making Democracy Work Civic Traditions in Modern Italy. Princeton University Press, Chichester.

Quiñones-Ruiz, X.F., Penker, M., Belletti, G., Marescotti, A., Scaramuzzi, S., 2016. Why early collective action pays off: evidence from setting protected geographical indications. Renewable Agric. Food Syst. 1, 1-14. http://dx.doi.org/10.1017/ S1742170516000168.

Schröck, R., 2014. Valuing country of origin and organic claim: a hedonic analysis of cheese purchases of German households. Br. Food J. 116 (7), 1070-1091. http://dx doi.org/10.1108/BFJ-12-2012-0308.

Shahidur, R.K., Gayatri, B.K., Hussain, A.S., 2010. Handbook on Impact Evaluation. Quantitative Methods and Practices. The World Bank Washington.

Tregear, A., Arfini, F., Belletti, G., Marescotti, A., 2007. Regional foods and rural development: the role of product qualification. J. Rural Stud. 23, 12-22. http://dx.doi.org/ 10.1016/j.jrurstud.2006.09.010.

Van Der Ploeg, J.D., Renting, H., Brunori, G., Knickel, K., Mannion, J., Marsden, T., De Roest, K., Sevilla-Guzman, E., Ventura, F., 2000. Rural development: from practices and policies towards theory. Sociologia Ruralis 40 (4). http://dx.doi.org/10.1111/ 1467-9523.00156. 391: 408.

Van Ittersum, K., Candel, J.J.M., Meulenberg, M., 2003. The influence of the image of a product's region of origin on product evaluation. J. Bus. Res. 56 (3), 215-226. http:// dx.doi.org/10.1016/S0148-2963(01)00223-5.

Velčovská, S., Sadílek, T., 2014. The system of geographical indication - Important component of the politics of the consumers' protection in European Union. Anfiteatru Econ. 16 (35), 228-242.

Wooldridge, J.M., 2013. Introductory econometric. A modern approach. South Western College Pub, Mason (Ohio).

World Bank, 2000. Handbook of Rural Development Indicators. The World Bank, Washington DC. 